\title{
A Comparative Study on the Cognitive Ability of the 1st Year and 6th Year (Interns) Pharmacy Students
}

\author{
Husain Gavande ${ }^{1}$ and Shambhavi Pandey ${ }^{2}$ \\ 'MRes Forensic Science, Faculty of Life Sciences and Medicines, \\ King's College London, London SE1 9NH; \\ hussain.gavandhe@gmail.com \\ ${ }^{2}$ Bachelor Of Pharmacy (Final Year), Bharati Vidyapeeth Deemed \\ University Erandwane, Pune - 411038, Maharashtra, India; \\ pandey.shambhavi19@gmail.com
}

\begin{abstract}
Cognition is concerned with the internal mental processes that begin with an external stimulus and result in a behavioral response. This study focuses on the assessment of the cognition of both $6^{\text {th }}$ year students and $1^{\text {st }}$ year students of Pharm. D (Doctor of Pharmacy 6 year integrated course), by using Addenbrooke's Cognitive Examination-Revised Edition (ACE-R). The test includes measurement of language, memory, attention and orientation, visuospatial, fluency skills which carry total 100 of the score. Methodology/ Material and Method: The comparative study for a year was carried out at a Pharmacy College, the subject enrolled were 120 Pharmacy students, the number of 60 students were from $1^{\text {st }}$ year, and remaining 60 were from the 6th year (Interns). The Addenbrooke's Cognitive Examination-Revised Edition (ACE-R) was used on the Fresher's who recently took admission in $1^{\text {st }}$ year of the Academics comparing it to the ACER-R test taken by the 6th year (Interns). The statistical inference was calculated from differences in Average Score and Standard Deviation, comparing these two groups to understand whether extensive use of cognition will increase the cognitive ability of individuals or deteriorate over the period span of 6 years under high stress and hard work. Result: Students in the $1^{\text {st }}$ year showed comparatively better cognitive ability through ACE-R scores (average score $=83.38 / 100$, standard deviation $=5.32$ ) than the $6^{\text {th }}$ year (average score $=78.63 / 100$, standard deviation $=5.55$ ) with the difference decline of $5.50 \%$ in the cognition and this difference was statistically very significant with the $p$-value. $[p=0.000354052][p<0.5]$. Conclusion: The cognitive ability of $6^{\text {th }}$ year Pharmacy students has shown a statistically significant difference in ACE-R scores as compare do $1^{\text {st }}$ year Pharmacy students, with a decline of 5.50\%, which suggests that extensive use of cognition, may result in idiosyncrasy due to various stressful situations over the period of 6 years, the reason found to be Academic, Carrier Pressure or maybe Poor Dormitory, Dietary Lifestyle.
\end{abstract}

Keywords: ACE-R. Cognition, Cognitive Study, Pharm.D

\section{Introduction}

The ability to attend to things in a selective and focused way, to concentrate over a period, to learn new information and skills, to plan, determine strategies for actions and execute them, to comprehend language and use verbal skills for communication and self-expression and to retain information and manipulate it to solve complex problems are examples of mental processes that are referred to as cognitive functions $s^{1}$. It is said that the more you use your cognitive ability, the better it becomes. Cognition is the psychological results of perception and learning and reasoning. Cognitive research has huge potential in India and can help us unravel mysteries of the human mind, identify etiopathogenesis and facilitate treatment of psychiatric disorders. Although the range of cognitive problems can be diverse, there are several cognitive domains, including executive function, attention

${ }^{*}$ Author for correspondence 
Table 1. The ACE raw scores obtained by the 1st year Doctor of Pharmacy Students

\begin{tabular}{|c|c|c|c|c|c|c|}
\hline $1^{\text {st }}$ year & Attention \& orientation & Memory & Fluency & Language & Visuospatial & Total \\
\hline 1. & 18 & 21 & 8 & 22 & 14 & 83 \\
\hline 2. & 18 & 16 & 11 & 14 & 15 & 74 \\
\hline 3. & 18 & 20 & 11 & 23 & 13 & 85 \\
\hline 4. & 17 & 22 & 11 & 23 & 14 & 87 \\
\hline 5. & 17 & 20 & 10 & 25 & 14 & 86 \\
\hline 6. & 14 & 24 & 11 & 23 & 15 & 87 \\
\hline 7. & 18 & 20 & 13 & 22 & 14 & 87 \\
\hline 8. & 12 & 20 & 8 & 23 & 13 & 76 \\
\hline 9. & 17 & 21 & 10 & 25 & 15 & 88 \\
\hline 10. & 18 & 24 & 11 & 22 & 14 & 89 \\
\hline 11. & 18 & 24 & 10 & 24 & 15 & 91 \\
\hline 12. & 18 & 17 & 7 & 23 & 12 & 77 \\
\hline 13. & 13 & 23 & 9 & 23 & 15 & 83 \\
\hline 14. & 16 & 20 & 13 & 25 & 10 & 84 \\
\hline 15. & 17 & 22 & 9 & 19 & 15 & 82 \\
\hline 16. & 16 & 20 & 6 & 21 & 15 & 78 \\
\hline 17. & 16 & 21 & 13 & 25 & 13 & 88 \\
\hline 18. & 18 & 21 & 8 & 22 & 14 & 83 \\
\hline 19. & 18 & 16 & 11 & 24 & 15 & 84 \\
\hline 20. & 18 & 20 & 11 & 23 & 13 & 85 \\
\hline 21. & 12 & 20 & 8 & 23 & 13 & 76 \\
\hline 22. & 18 & 24 & 11 & 22 & 14 & 89 \\
\hline 23. & 17 & 22 & 11 & 23 & 14 & 87 \\
\hline 24. & 18 & 20 & 11 & 23 & 13 & 85 \\
\hline 25. & 17 & 21 & 8 & 21 & 14 & 81 \\
\hline 26. & 17 & 20 & 10 & 25 & 14 & 86 \\
\hline 27. & 15 & 18 & 6 & 23 & 14 & 76 \\
\hline 28. & 16 & 21 & 13 & 25 & 13 & 88 \\
\hline 29. & 17 & 22 & 11 & 23 & 14 & 87 \\
\hline 30. & 17 & 22 & 11 & 23 & 14 & 87 \\
\hline 31. & 18 & 21 & 8 & 22 & 14 & 83 \\
\hline 32. & 14 & 11 & 8 & 18 & 13 & 64 \\
\hline 33. & 16 & 20 & 6 & 24 & 14 & 80 \\
\hline 34. & 16 & 20 & 5 & 24 & 14 & 79 \\
\hline 35. & 16 & 20 & 6 & 23 & 14 & 79 \\
\hline 36. & 16 & 21 & 13 & 25 & 13 & 88 \\
\hline 37. & 18 & 16 & 11 & 24 & 15 & 84 \\
\hline 38. & 18 & 20 & 11 & 23 & 13 & 85 \\
\hline 39. & 17 & 21 & 14 & 25 & 15 & 92 \\
\hline 40. & 17 & 21 & 8 & 21 & 15 & 82 \\
\hline
\end{tabular}


Table 1. (Continued)

\begin{tabular}{|c|c|c|c|c|c|c|}
\hline $1^{\text {st }}$ year & Attention \& orientation & Memory & Fluency & Language & Visuospatial & Total \\
\hline 41. & 18 & 20 & 11 & 23 & 13 & 85 \\
\hline 42. & 17 & 20 & 10 & 25 & 14 & 86 \\
\hline 43. & 18 & 21 & 8 & 22 & 14 & 83 \\
\hline 44. & 16 & 20 & 6 & 23 & 14 & 79 \\
\hline 45. & 18 & 21 & 8 & 22 & 14 & 83 \\
\hline 46. & 18 & 16 & 11 & 24 & 15 & 84 \\
\hline 47. & 17 & 21 & 14 & 25 & 14 & 91 \\
\hline 48. & 16 & 20 & 6 & 24 & 14 & 80 \\
\hline 49. & 15 & 12 & 11 & 20 & 15 & 73 \\
\hline 50. & 16 & 20 & 6 & 23 & 14 & 79 \\
\hline 51. & 18 & 20 & 11 & 23 & 13 & 85 \\
\hline 52. & 18 & 21 & 14 & 25 & 16 & 94 \\
\hline 53. & 15 & 12 & 11 & 20 & 14 & 72 \\
\hline 54. & 18 & 21 & 8 & 22 & 14 & 83 \\
\hline 55. & 17 & 20 & 10 & 25 & 14 & 86 \\
\hline 56. & 18 & 20 & 11 & 23 & 13 & 85 \\
\hline 57. & 16 & 20 & 6 & 24 & 14 & 80 \\
\hline 58. & 18 & 16 & 11 & 24 & 15 & 84 \\
\hline 59. & 16 & 20 & 6 & 23 & 14 & 79 \\
\hline 60. & 18 & 17 & 13 & 24 & 16 & 88 \\
\hline Total & 1006 & 1191 & 583 & 1375 & 839 & 4994 \\
\hline Avg. & 17 & 20 & 10 & 23 & 14 & 83.23 \\
\hline
\end{tabular}

and information processing and working memory, which appear more frequently at risk 2 . In this study, the cognitive ability of $6^{\text {th }}$ year (Interns) pharmacy students are compared with that of the $1^{\text {st }}$ year. (Freshers) Pharmacy students. The cognitive ability of the $6^{\text {th }}$ year students should be more as compared to the $1^{\text {st }}$ years' students since they have been involved in pharmacy education from the last five years, whereas the 1st year students came directly after their 12th standard (Schooling). However, there are other possibilities that the results can be otherwise, for instants: The $1^{\text {st }}$ year students have more cognitive ability than $6^{\text {th }}$ years, due to the fact that the $1^{\text {st }}$ years students are freshers and are excited as they experience the college, new atmosphere, new friends, etc., whereas $6^{\text {th }}$ years are tired of studying and doing routine works, over the last 5 years and are much relaxed since they are almost done with their course and done with all the exams. Alternatively, on the contrary, that $1^{\text {st }}$ year students are struggling to get adjusted to this new college atmosphere and hence, their cognition is comparatively low. The cognition of both $6^{\text {th }}$ year students and $1^{\text {st }}$ year students are assessed by using Addenbrooke's Cognitive Examination (ACE). It is a global cognitive bedside test introduced in 1997 at Addenbrooke's (Cambridge) and revised in 2006. The ACE detects early dementia and reliably distinguishes between frontotemporal dementia and Alzheimer's disease and other conditions, including affective disorders. It has been adopted in 140 countries and is freely available in different languages. The test includes measurement of language, memory, attention, and orientation, visuospatial, fluency skills which carry total 100 of a score. $\frac{3-5}{}$

\subsection{Addenbrooke's Cognitive Examination (ACEIII)}

It contains five subscores, each one representing one cognitive domain: viz. Attention/ Orientation (18 points) Memory 
Table 2. The ACE raw scores obtained by the $6^{\text {th }}$ year Doctor of Pharmacy Students

\begin{tabular}{|c|c|c|c|c|c|c|}
\hline $6^{\text {th }}$ year & Attention \& orientation & Memory & Fluency & Language & Visuospatial & Total \\
\hline 1. & 16 & 18 & 7 & 24 & 14 & 79 \\
\hline 2. & 13 & 24 & 9 & 24 & 13 & 83 \\
\hline 3. & 14 & 11 & 9 & 18 & 14 & 66 \\
\hline 4. & 18 & 14 & 9 & 24 & 14 & 79 \\
\hline 5. & 18 & 19 & 11 & 26 & 14 & 88 \\
\hline 6. & 17 & 23 & 9 & 18 & 13 & 80 \\
\hline 7. & 18 & 18 & 10 & 23 & 14 & 83 \\
\hline 8. & 18 & 20 & 10 & 20 & 12 & 80 \\
\hline 9. & 16 & 24 & 11 & 24 & 16 & 91 \\
\hline 10. & 16 & 20 & 6 & 24 & 14 & 80 \\
\hline 11. & 15 & 12 & 11 & 22 & 14 & 74 \\
\hline 12. & 15 & 15 & 8 & 21 & 15 & 74 \\
\hline 13. & 14 & 22 & 13 & 24 & 15 & 88 \\
\hline 14. & 15 & 16 & 7 & 21 & 14 & 73 \\
\hline 15. & 17 & 21 & 7 & 25 & 16 & 86 \\
\hline 16. & 16 & 21 & 12 & 23 & 13 & 85 \\
\hline 17. & 18 & 20 & 11 & 25 & 15 & 89 \\
\hline 18. & 18 & 21 & 8 & 22 & 14 & 83 \\
\hline 19. & 18 & 16 & 11 & 24 & 15 & 84 \\
\hline 20. & 18 & 20 & 11 & 23 & 13 & 85 \\
\hline 21. & 15 & 15 & 8 & 21 & 15 & 74 \\
\hline 22. & 15 & 15 & 8 & 22 & 15 & 75 \\
\hline 23. & 16 & 20 & 6 & 24 & 14 & 80 \\
\hline 24. & 16 & 20 & 6 & 23 & 13 & 78 \\
\hline 25. & 16 & 20 & 6 & 24 & 14 & 80 \\
\hline 26. & 15 & 15 & 8 & 21 & 15 & 74 \\
\hline 27. & 16 & 20 & 6 & 23 & 14 & 79 \\
\hline 28. & 18 & 21 & 8 & 22 & 14 & 83 \\
\hline 29. & 16 & 20 & 6 & 23 & 14 & 79 \\
\hline 30. & 16 & 20 & 6 & 24 & 14 & 80 \\
\hline 31. & 15 & 15 & 8 & 22 & 15 & 75 \\
\hline 32. & 16 & 20 & 6 & 24 & 14 & 80 \\
\hline 33. & 13 & 17 & 5 & 18 & 11 & 64 \\
\hline 34. & 15 & 15 & 8 & 21 & 15 & 74 \\
\hline 35. & 18 & 21 & 8 & 22 & 14 & 83 \\
\hline 36. & 16 & 20 & 6 & 22 & 13 & 77 \\
\hline 37. & 15 & 15 & 8 & 22 & 15 & 75 \\
\hline 38. & 16 & 20 & 6 & 22 & 14 & 78 \\
\hline 39. & 18 & 21 & 8 & 22 & 14 & 83 \\
\hline 40. & 15 & 15 & 8 & 21 & 15 & 74 \\
\hline
\end{tabular}


Table 2. (Continued)

\begin{tabular}{|c|c|c|c|c|c|c|}
\hline $6^{\text {th }}$ year & Attention \& orientation & Memory & Fluency & Language & Visuospatial & Total \\
\hline 41. & 14 & 19 & 5 & 20 & 13 & 71 \\
\hline 42. & 14 & 19 & 5 & 20 & 12 & 70 \\
\hline 43. & 16 & 20 & 6 & 22 & 14 & 78 \\
\hline 44. & 14 & 19 & 5 & 20 & 13 & 71 \\
\hline 45. & 16 & 20 & 6 & 24 & 14 & 80 \\
\hline 46. & 18 & 20 & 11 & 23 & 13 & 85 \\
\hline 47. & 18 & 20 & 11 & 23 & 14 & 86 \\
\hline 48. & 18 & 20 & 11 & 23 & 13 & 85 \\
\hline 49. & 16 & 20 & 6 & 22 & 15 & 79 \\
\hline 50. & 17 & 21 & 8 & 22 & 14 & 82 \\
\hline 51. & 15 & 15 & 8 & 21 & 15 & 74 \\
\hline 52. & 15 & 15 & 8 & 21 & 14 & 73 \\
\hline 53. & 16 & 20 & 6 & 23 & 13 & 78 \\
\hline 54. & 16 & 20 & 6 & 22 & 14 & 78 \\
\hline 55. & 16 & 19 & 6 & 23 & 14 & 78 \\
\hline 56. & 14 & 19 & 5 & 20 & 12 & 70 \\
\hline 57. & 15 & 15 & 8 & 22 & 15 & 75 \\
\hline 58. & 16 & 20 & 6 & 22 & 14 & 78 \\
\hline 59. & 15 & 15 & 8 & 21 & 14 & 73 \\
\hline 60. & 16 & 20 & 6 & 24 & 14 & 80 \\
\hline Total & 959 & 1116 & 470 & 1336 & 838 & 4719 \\
\hline Avg. & 16 & 19 & 8 & 19 & 14 & 78.65 \\
\hline
\end{tabular}

From Table 1 and Table 2, Summary: It can be inferred that 1st year Doctor of Pharmacy Students has more cognitive ability in almost all cognitive parameters except for visuospatial than the 6th year Doctor of Pharmacy Students.

(26 points), Fluency (14 points), Language (26 Points) and Visuospatial (16 Points). It takes between 15 and 20 min to administer and score the test. The ACE-R maximum score is 100 , calculated by the addition of all domains. The participants were asked to answer the question in the ACE III and answers were computed and analyzed ${ }^{6}$.

\section{Purpose of the Study}

To understand whether the extensive use of cognition will increase the cognitive ability of individuals.

\section{Objective}

To identify the difference in the cognitive ability of junior most and the senior most students in a Pharmacy School.

\section{Methodology}

\subsection{Aim}

To compare the ACE scores of the 1st year Pharmacy students and the 6th year Pharmacy, students. Table 1 and 2 .

\subsection{Sample Size}

A total number of 120 students were enrolled in the study from a pharmacy school, where 60 students are from the $1^{\text {st }}$ year and remaining 60 from the $6^{\text {th }}$ year (Interns).

\subsection{Method of Data Collection}

$\mathrm{ACE}$ is in the form of a questionnaire which is given and assessed to all the 120 students individually. 


\section{- Inclusion:}

- Students of $1^{\text {st }}$ year and $6^{\text {th }}$ year Doctor of Pharmacy. (Doctor of Pharmacy is a six year integrated pharmacy course)

- The students are above 18 years and below 25 years of age.

\section{- Exclusion:}

- Students who attended JEE or NEET Examination.

- Students with any history of depression and anxiety and other learning disabilities.

\subsection{Data Collection and Analysis}

Comparison is made between the $1^{\text {st }}$ year's and $6^{\text {th }}$ year's scores to obtain significant results, by finding the difference in their Arithmetic Mean.

\section{Result}

Students in $1^{\text {st }}$ year showed comparatively better cognitive ability through ACE-R scores (average score $=83.38 / 100$,

Table 3. Difference in Scores concerning Cognitive Parameters $^{-}$, it is seen that the cognitive parameters of $1^{\text {st }}$ year Pharm.D students are more than $6^{\text {th }}$-year Pharm.D students except for the visuospatial parameter. (The data collected in the study is supported by studies conducted by Vankatshiva Reddy, et al. 2012.)

\begin{tabular}{|c|c|c|c|}
\hline \multicolumn{2}{|c|}{ Cognitive Parameters } & \multirow{2}{*}{$\frac{1^{\text {st }} \text { year }}{17.00}$} & \multirow{2}{*}{$\frac{6^{\text {th }} \text { year }}{16.00}$} \\
\hline $\begin{array}{l}\text { Attention \& } \\
\text { orientation }\end{array}$ & $\begin{array}{c}\text { Score (Avg.) } \\
\text { Out of } 18\end{array}$ & & \\
\hline & Percentage (\%) & $94.00 \%$ & $89.00 \%$ \\
\hline \multirow[t]{2}{*}{ Memory } & $\begin{array}{c}\text { Score (Avg.) } \\
\text { Out of } 26\end{array}$ & 20.00 & 19.00 \\
\hline & Percentage (\%) & $77.00 \%$ & $73.00 \%$ \\
\hline \multirow[t]{2}{*}{ Fluency } & $\begin{array}{c}\text { Score (Avg.) } \\
\text { Out of } 14\end{array}$ & 10.00 & 8.00 \\
\hline & Percentage (\%) & $71.00 \%$ & $57.00 \%$ \\
\hline \multirow[t]{2}{*}{ Language } & $\begin{array}{c}\text { Score (Avg.) } \\
\text { Out of } 26\end{array}$ & 23.00 & 19.00 \\
\hline & Percentage (\%) & $88.00 \%$ & $73.00 \%$ \\
\hline \multirow[t]{2}{*}{ Visuospatial } & $\begin{array}{c}\text { Score (Avg.) } \\
\text { Out of } 16\end{array}$ & 14.00 & 14.00 \\
\hline & Percentage (\%) & $87.50 \%$ & $87.50 \%$ \\
\hline \multirow[t]{2}{*}{ Total } & $\begin{array}{c}\text { Score (Avg.) } \\
\text { Out of } 100\end{array}$ & 83.38 & 78.63 \\
\hline & Percentage (\%) & $83.38 \%$ & $78.63 \%$ \\
\hline \multicolumn{2}{|c|}{ DIFFERENCE (\%) } & \multicolumn{2}{|c|}{$5.50 \%$} \\
\hline
\end{tabular}

Table 4. Differences in ACE-R scores for both groups Statistics: Scores obtained from ACE-R examination were used for assessing and comparing effects on cognition. Mean improvement in ACE-R scores (Total and from individual domains namely Attention and orientation, Memory, Language, Fluency, and Visuospatial) were calculated. P-value was calculated using the differences in initial and final scores of both groups as two different sample sets. $\stackrel{?}{-}$

\begin{tabular}{|c|c|c|}
\hline Parameters & 1st year & 6th year \\
\hline Average Mean & $\mathbf{8 3 . 2 3 3 3 3 3 3 3}$ & $\mathbf{7 8 . 6 5}$ \\
\hline Standard Deviation & 5.324604439 & 5.556565822 \\
\hline Variances & 28.35141243 & 30.87542373 \\
\hline P - Value & \multicolumn{2}{|c|}{$\mathbf{0 . 0 0 0 3 5 4 0 5 2}$} \\
\hline
\end{tabular}

standard deviation $=5.32)$ than $6^{\text {th }}$ year (average score $=$ $78.63 / 100$, standard deviation $=5.55)$ with the decline of $5.50 \%$ in the cognition and this difference were statistically significant $[p=0.000354052][p<0.5]$. Tables 3 and 4 .

\section{Discussion}

Cognition is an important factor that influences information processing and execution. It is impaired in most of the students, due to stress, anxiety, poor dietary lifestyle and substance abuse. The study site is Poona College of Pharmacy, a Pharmacy College that receives students from all over India with a different culture, ethnic and from moderate to high economic background. Amongst the subjects included, 57 are male (48\%) and 63 females (52\%). Indian females are more encouraged for education as compared to the last ten years of graph and statistics.

Amongst the included subjects, belong to young age group $<18$ years - 46 (38\%) followed by 19-20 years- 14 (12\%), 21-25 years - 55(46\%) and 27-30 years-5 (\%). In a study, "Indian Psychiatric Epidemiologic Studies: Learning from the past Suresh Bada Math, Ravindra Srinivasaraju - Indian Journal of Psychiatry- 2010" young age group has been maximally affected by psychiatric illnesses which are not different when compared to studies conducted in other countries. The epidemiologic study conducted in Pune also supports the evidence. Table 5.

Deficits of attention, emotion and cognition occur in individuals with alcohol abuse and addiction. Recent research reports compromised microstructural and functional network connectivity in alcoholism, which can influence the dynamic tuning between brain systems, e.g. the frontally based executive control system, the limbic 
emotion system and the midbrain-striatal reward system, thereby impeding cognitive flexibility and behavioral adaptation to changing environments ${ }^{7}$.

Addenbrooke's cognitive examination was administered once the subject was admitted in the curriculum, one week after the inclusion of 60 subjects and rest 60 were from 6th year. Average ACE-R scores for subjects in 1 st year is $83.23 / 100$ and Average scores for patients who were in the 6th year showed $78.65 / 100$, the percent decline in the cognition is $5.50 \%$.

Deterioration in all the cognitive parameters was observed from $1^{\text {st }}$ year to $6^{\text {th }}$ year and except visuospatial aspect tend to be constant at $87 \%$ followed by decline in the graph, Attention and Orientation 94-89 (5.32\%), Memory 77-73 (5.48\%), Fluency 71-57 (19.72\%), Language 88-73 (17.05\%). Figure 1.

Table 5. Demographic distribution of enrolled subject,as seen above in the table is the demographic distribution of the enrolled patients and $45 \%$ of the patients are both smoker and alcoholic, which can be one of the factors, leading to declining in cognition

\begin{tabular}{|c|c|c|}
\hline $\begin{array}{l}\text { Respondent's } \\
\text { characteristic }\end{array}$ & $\begin{array}{c}\text { Number of } \\
\text { patients }\end{array}$ & Percentage (\%) \\
\hline \multicolumn{3}{|l|}{ Subjects Included } \\
\hline 1st year PharmD & 60 & $50 \%$ \\
\hline 6th year PharmD & 60 & $50 \%$ \\
\hline \multicolumn{3}{|l|}{ Gender } \\
\hline Male & 57 & $48 \%$ \\
\hline Female & 63 & $52 \%$ \\
\hline \multicolumn{3}{|l|}{ Age (years) } \\
\hline (<18 years) & 46 & $38 \%$ \\
\hline (19-20 years) & 14 & $12 \%$ \\
\hline (21-25 years) & 55 & $46 \%$ \\
\hline$(27-30$ years $)$ & 5 & $4 \%$ \\
\hline \multicolumn{3}{|l|}{ Marital Status } \\
\hline Married & 7 & $6 \%$ \\
\hline Unmarried & 113 & $94 \%$ \\
\hline \multicolumn{3}{|l|}{ Place of Resident } \\
\hline Urban & 73 & $61 \%$ \\
\hline Rural & 47 & $39 \%$ \\
\hline \multicolumn{3}{|l|}{ Social Habit } \\
\hline Smoker & 12 & $10 \%$ \\
\hline Alcoholic & 24 & $20 \%$ \\
\hline Both & 54 & $45 \%$ \\
\hline None & 30 & $25 \%$ \\
\hline
\end{tabular}

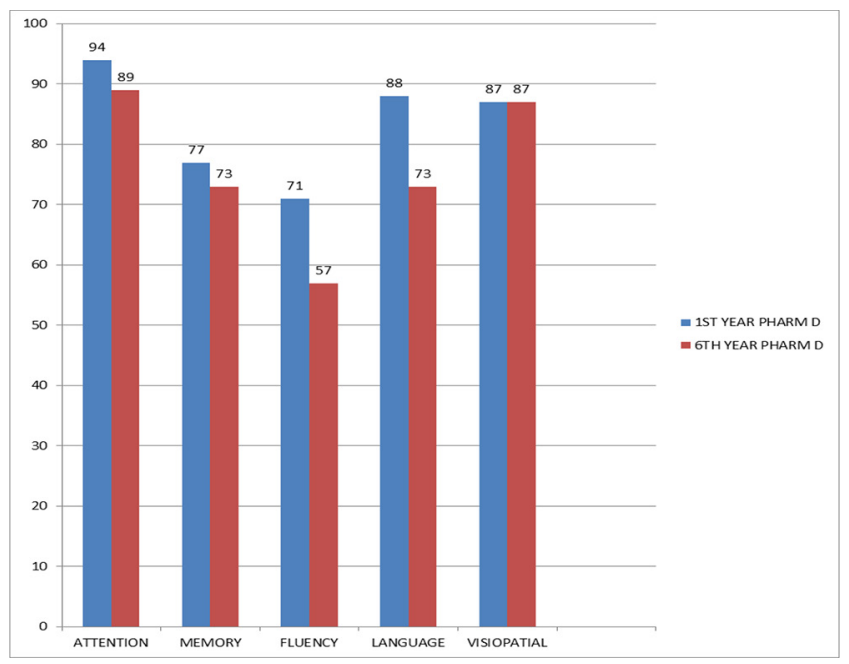

Figure 1. Comparison of the cognitive parameters of $1^{\text {st }}$ Year Doctor of Pharmacy Students and $6^{\text {th }}$ Year Doctor of Pharmacy Students.

\section{Conclusion}

This study concludes that the cognitive ability of $6^{\text {th }}$-year students is less than $1^{\text {st }}$ year students (T3). The cognitive ability of $6^{\text {th }}$ year Pharmacy students has shown a statistically significant difference in ACE-R scores as compared to $1^{\text {st }}$ year Pharmacy students, with a decline of $5.50 \%$, which suggests that extensive use of cognition, may result in idiosyncrasy due to various stressful situations over the period of 6 years, the reason found to be Academic Pressure, Poor eating Habits, Substance Abuse, Carrier Pressure or maybe Poor Dormitory Lifestyle. It is also considered that the $6^{\text {th }}$ years are tired of studying and

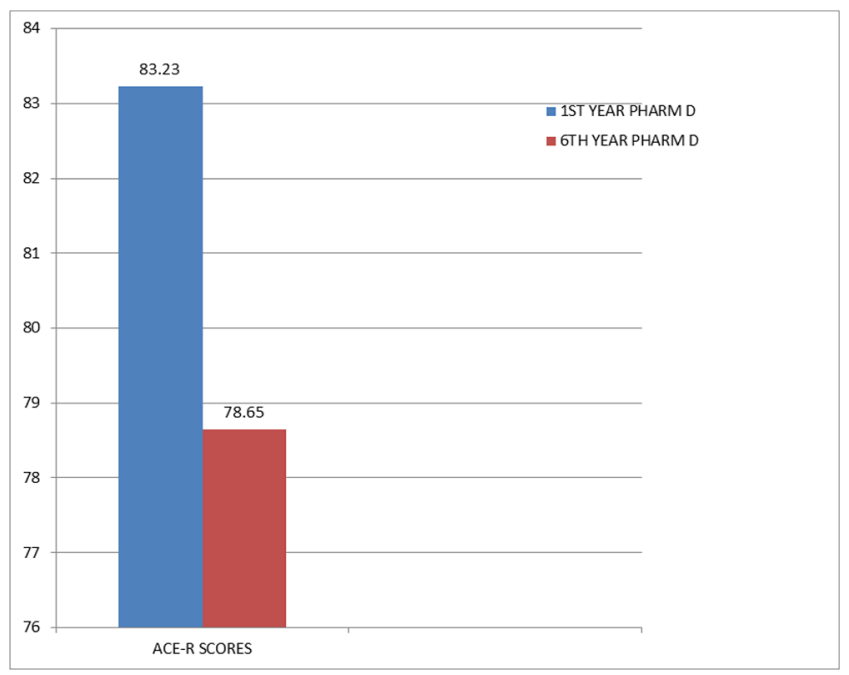

Figure 2. Cognition level of Pharmacy Students at the beginning and end of the course. 
doing routine works, over the last five years, and are much relaxed since they are almost done with their course and done with all the exams, hence their cognition is less as compared to the 1st years. Figure 2.

\section{Reference}

1. Dalal PK, Sivakumar T. Cognitive psychiatry in India. India J Psychiatry. 2010; 52:SI2835.

2. Trivedi JK, Gupta PK, Saha R. Indian psychiatry, research and Asian countries. Indian J Psychiatry. 2010; 52:S68-71.

3. Larner AJ. Dementia Clinical Practice: A Neurological Perspective: Studies in the Dementia Clinic. Springer. 2012 Jan. p. 31. ISBN 978-1-4471-2361.

4. Puri B, Treasaden I. Psychiatry: An evidence-based text. CRC Press. 2009 Nov. p. 515. ISBN 978-0-340-95005-0.
5. Segen's Medical Dictionary.

6. Krishna Kumar S, Rajaram S, Rajendran P, Ismail M, Thirumalaikolundu Subramanian P. A comparative study of cognitive function and Information Processing Ability among Type 2 Diabetes Mellitus Patients and Healthy volunteers. Journal of Evolution and Dental Sciences. 2014; 4(37).

7. Muller-Oehring EM, Schulte T. Cognition, emotion and attention. Handbook of Clinical Neurology. 2014; 125: 341-54. 10.1016/B978-0-444-62619-6.00020-3. https://doi. org/10.1016/B978-0-444-62619-6.00020-3

8. Studies conducted by Vankatashiva Reddy, et al. 2012.

9. Gavande HM. Study on effects of psychotropic drug with and without electroconvulsive therapy on Cognition. Indian Journal of Medical Research and Pharmaceutical Sciences, 2017 Jun; 4(6):55-62. 